\title{
ASPECTOS DA MODERNIZAÇÃO DO ENSINO SUPERIOR BRASILEIRO E CRÍTICA AO MÉTODO CIENTÍFICO: APROXIMAÇÕES COM O PROCESSO DE NATURALIZAÇÃO DA PESQUISA EM EDUCAÇÃO
}

\author{
Sérgio Rafael Barbosa da Silva
}

\begin{abstract}
Resumo:
O tema central do artigo é a produção do conhecimento científico na educação superior. Seu objetivo é continuar uma trajetória de interrogação sobre os pressupostos do processo de conhecimento em educação, examinando, agora, a construção histórica do objeto. Esse exame é realizado a partir da discussão de elementos da análise de Florestan Fernandes e Miriam Cardoso sobre o processo de produção do conhecimento científico no Brasil.
\end{abstract}

Palavras-chave: Ensino Superior; Método Científico; Pesquisa em Educação.

\begin{abstract}
:
The central theme of this paper is the production of scientific knowledge in higher education. Our main aim is to put forward a questioning trajectory on the foundations of the process of knowledge in education, examining, at this moment, the object's historical construction. This approach is performed departing from the discussion of elements of the Florestan Fernandes and Miriam Cardoso analysis on the process of production of scientific knowledge in Brazil.
\end{abstract}

Keywords: Higher education, Scientific method, Educational research.

\section{Introdução}

Esse artigo tem a finalidade de apresentar algumas ideias que estão me ajudando na construção de uma problemática para a pesquisa que estou desenvolvendo no curso de doutorado em educação. A minha pesquisa de doutorado está em fase inicial e, a meu ver, o debate sobre as ideias que apresentarei a seguir irá contribuir na definição da problemática da minha pesquisa.

De forma geral, apresentarei alguns aspectos da modernização do ensino superior brasileiro entre as décadas de 1930 e 1970 e, em seguida, a crítica que Miriam Limoeiro Cardoso faz à crença de que o método científico, por si mesmo, garante a 
apreensão de conceitos que definem um objeto real. Entendo que os momentos mencionados anteriormente me ajudarão a situar o meu objeto de pesquisa - inflexões teóricas nos programas de pós-graduação em educação - no tempo histórico a partir de algumas questões políticas e teórico-metodológicas que formaram o contexto das pesquisas em educação nas décadas de 1960 e 1970.

Ao levantar essas questões estou estabelecendo alguns limites daquilo que denomino de naturalização da pesquisa em educação, nesse sentido, esse artigo não é um trabalho que pretende apresentar a síntese dos resultados de uma pesquisa já realizada, pelo contrário, ele tem a característica de levantar questões que irão auxiliar no desenvolvimento de uma pesquisa de doutorado que ainda está definindo sua problemática de pesquisa.

\section{Aspectos da modernização do ensino superior brasileiro}

Para iniciarmos a discussão sobre a modernização do ensino superior brasileiro entre as décadas de 1930 e 1970, nos baseamos na contribuição de Florestan Fernandes no livro intitulado Universidade brasileira: reforma ou revolução. Nesse livro o autor faz uma análise do ensino superior brasileiro até a década de 1970. Em sua análise apresenta, dentre outros, o conceito de padrão brasileiro de escola superior, um padrão que identifica a passagem, através de reformas legais como o Estatuto da Universidade Brasileira decretado por Francisco Campos em 1931, do ensino superior tradicional para a universidade conglomerada, incluindo as experiências acadêmicas da Universidade de São Paulo (USP), criada em 1934 e da Universidade do Distrito Federal (UDF), criada em 1935.

Segundo Fernandes (1975) o padrão brasileiro de escola superior teve o seu ápice entre as décadas de 1930 e 1960 e pode ser caracterizado como uma justaposição dos seguintes elementos: o funcionamento das faculdades, ou escolas superiores, isoladas; o funcionamento das universidades conglomeradas; e a maneira como a ideia de universidade foi interpretada no país. Neste cenário de justaposição afirma que a classe dominante no Brasil utilizou o ensino superior para manter o monopólio social do poder político e cultural; a universidade foi um local privilegiado para formar as elites dirigentes, e secundariamente, exerceu outras funções.

No entanto, críticas foram feitas ao modelo de ensino superior adotado pelo Brasil a partir da década de 1930. Essas críticas começaram a se intensificar com a

\begin{tabular}{|l|l|l|l|l|}
\hline Revista Dialectus & Ano 1 & n. 2 & Janeiro-Junho 2013 & p. 211-227 \\
\hline
\end{tabular}


atuação da Associação Brasileira de Educação (ABE), da Academia Brasileira de Ciências (ABC) e do movimento dos Pioneiros da Educação Nova (FÁVERO, 2006). Mas elas ganharam relevo quando os estudantes universitários nas décadas de 1940 e 1950, liderados pela União Nacional dos Estudantes (UNE), perceberam que as críticas liberais dos setores mencionados anteriormente impulsionaram um processo de modernização e reforma da universidade brasileira sem, no entanto, conseguirem criar uma universidade que constituísse um complexo sistema institucional. Para Fernandes (1975, p. 160):

\begin{abstract}
A partir daí, ganhou relevo a concepção de que a universidade constitui um complexo sistema institucional, dotado de organização estrutural-funcional pluridiferenciada e de dinamismos de auto-crescimentos duplamente polarizados [...]. Não só a "função de ensinar" passava a ser concebida como uma função a ser desdobrada e diversificada, de modo a inserir-se o ensino pós-graduado entre as tarefas centrais da universidade.
\end{abstract}

Neste contexto, o entendimento de que a universidade brasileira não era uma organização pluridiferenciada, como algumas universidades de alguns países da América Latina, da América do Norte e da Europa, levou os estudantes a afirmarem que a mudança da estrutura da universidade brasileira não mudaria sem uma mudança da estrutura social. A radicalização do movimento dos estudantes desencadeou um movimento pela reforma universitária. Esse movimento se insere no momento histórico em que o Brasil estava caminhando na direção de um processo de modernização de sua economia e a universidade era uma instituição da sociedade que necessitava ser modernizada.

Mas, acontecimentos políticos - a renúncia do presidente Jânio Quadros, a posse de João Goulart e, posteriormente, a tensão causada pelas discussões em torno das "reformas de base". Reformas defendidas pelo presidente João Goulart - no início da década de 1960 contribuíram, não só, para a tomada do poder de Estado pelo golpe militar em 1964, retirando os estudantes da cena política e deixando o caminho aberto para que a reforma universitária fosse realizada segundo os moldes das forças conservadoras, bem como, contribuíram para que a mudança da estrutura social fosse associada ao processo de modernização do país, como se esse processo fosse sinônimo de mudança social (cf. FERNANDES, 1975).

Em sua análise, Fernandes se detém nos fatores que antecederam a reforma universitária, concretizada na Lei $\mathrm{n}^{\circ} 5.540 / 68$, que o autor denomina de reforma universitária consentida. Contudo, apesar da crítica, reconhece que a referida lei possui 
avanços em relação ao padrão universitário brasileiro por tratar as universidades como integradas e multifuncionais.

A análise de Fernandes também ajuda a entender o contexto político que orientou a execução da legislação educacional do ensino superior nos anos de 1960, especificamente, os Pareceres no 977/65 e n 77/69, da Câmara de Educação Superior (CES), do Conselho Federal de Educação (CFE).

Através da análise desses pareceres, é possível afirmar que eles se completam. O Parecer $n^{\circ} 977 / 65$ possui a finalidade de definir a natureza da pós-graduação brasileira e o Parecer $n^{\circ} 77 / 69$ estabelece as normas desse nível. De uma forma geral, eles procuram preencher uma lacuna no ensino superior brasileiro, ou seja, eles objetivam conseguir superar a falta de tradição que o país possui no ensino pós-graduado. Para superar essa falta de tradição era necessário "introduzir na universidade uma espécie de diversificação vertical com o escalonamento de níveis de estudo que vão desde o ciclo básico, à pósgraduação" (PARECER, 977/65, p. 164).

Neste contexto, somos levados a indagar como se explica o fato de a reforma universitária, defendida pelos estudantes, e de os Pareceres $n^{\circ}$ 977/65 e no 77/69 e a Lei 5.540/68, elaborados pelas forças conservadoras, tal como afirma Fernandes (1975), afirmarem a necessidade de instituir uma verticalização na universidade brasileira.

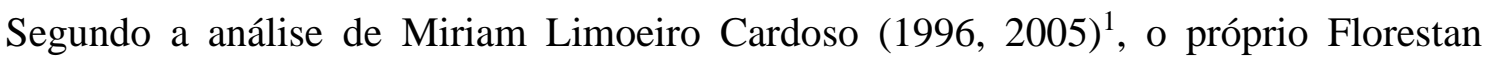
Fernandes responde essa questão ao elaborar a categoria de capitalismo dependente.

De acordo com Cardoso, a categoria de capitalismo dependente permite compreendermos aquilo que ficou denominado como modernização. Essa categoria foi formulada quando Florestan Fernandes começa a afirmar que existem determinações históricas presentes na sociedade brasileira que estão além dos limites nacionais. Ao trabalhar com essa idéia, Florestan Fernandes desloca a perspectiva do objeto de sua análise, passando a trabalhar com a totalidade modo de produção capitalista.

Dessa forma, Fernandes, segundo Cardoso, insere a sociedade nacional nessa totalidade denominada civilização ocidental moderna ou capitalismo moderno. Com essa nova referência para pensar a sociedade brasileira, Cardoso afirma que Florestan Fernandes, "[...] constrói um novo problema para a sua pesquisa: o da relação entre a sociedade brasileira e a expansão mundial do capitalismo" (CARDOSO, 2005, p. 10).

\footnotetext{
${ }^{1}$ Nesses trabalhos a autora realiza uma apresentação da contribuição teórica de Florestan Fernandes com destaque para a reconstrução do objeto das pesquisas desenvolvidas por ele até chegar ao conceito de capitalismo dependente.
}

\begin{tabular}{|l|l|l|l|l|}
\hline Revista Dialectus & Ano 1 & n. 2 & Janeiro-Junho 2013 & p. 211-227 \\
\hline
\end{tabular}


Nessa mudança de perspectiva, o que era tratado como nacional e internacional passa a ser tratado como elementos que fazem parte do ordenamento capitalista do mundo e da expansão dessa ordem. Agora, o fator principal da análise sociológica de Florestan Fernandes é: “[...] as influências estruturais e dinâmicas da ordem social global sobre a absorção e a expansão do capitalismo no Brasil" (FERNANDES apud CARDOSO, 2005, p. 10). Ao prosseguir na sua teorização, Florestan Fernandes constrói a caracterização da "forma de integração "das sociedades heteronômicas ou dependentes" aos "centros de dominância" da expansão econômica capitalista" (Ibidem,

p. 11). Segundo Cardoso, para Florestan Fernandes, o desenvolvimento capitalista, nas economias dependentes, assume uma forma específica e particular denominada capitalismo dependente, sendo essa forma, uma das formas que o desenvolvimento capitalista assume na fase monopolista:

Daí porque não cabe, pois, tomar diretamente para análise a relação entre um
Estado-nação particular, no caso o Brasil, e o capitalismo enquanto modo de
produção, como se se tratasse de uma relação de determinação direta e
exaustiva de um geral sobre um particular desse geral. Antes, é preciso
identificar a forma de integração específica desse particular ao sistema a que
se vincula e que o determina, ou seja, quanto ao Brasil e à América Latina
segundo a forma de integração capitalista heteronômica ou dependente.
(CARDOSO, 2005, p. 12).

Na análise de Florestan Fernandes, a história não aparece como uma evolução natural de fatos: "[...] é falsa a ideia de que a história se faz, que ela se determina automaticamente. A história é feita coletivamente pelos homens e, sob o capitalismo, através de conflitos de classe de alcance local, regional, nacional e mundial" (FERNANDES apud CARDOSO, 2005, p. 18). Neste caso, segundo Cardoso, a categoria de capitalismo dependente articula o sistema de classes, nacional e internacional, para compreender o funcionamento da condição de heteronomia e questionar essa condição, para poder chegar aos seus determinantes históricos: "[...] pois é a partir dessa inclusão que as burguesias locais são admitidas como partes importantes daquela articulação. [...], Florestan identifica as burguesias locais como parceiras das burguesias hegemônicas parceiras menores e subordinadas, mas parceiras" (CARDOSO, 2005, p.18).

Em resumo, Florestan Fernandes, ao elaborar o conceito de capitalismo dependente, não se baseia em uma relação sistêmica, por exemplo, a relação de centro e periferia, ou seja, não compreende que a dependência se trata de um mecanismo de relações entre partes diferentes de um mesmo sistema. Ele opera com a dependência dentro do sistema de produção capitalista indicando que a dependência é uma variante

\begin{tabular}{|l|l|l|l|l|} 
Revista Dialectus & Ano 1 & n. 2 & Janeiro-Junho 2013 & p. 211-227 \\
\hline
\end{tabular}


desse sistema, ou seja, introduz, em caráter permanente, a associação da dependência ao desenvolvimento do capitalismo na fase monopolista:

\begin{abstract}
A condição colonial permanece, ao permanecer (ou, quem sabe, para permanecer) muda de forma a cada nova fase do desenvolvimento capitalista. Fala em colonialismo, imperialismo e capitalismo monopolista. O que toma para a análise é especialmente a heteronomia nessa última fase, definindo-a enquanto capitalismo dependente. [...]. Cada mudança de fase do capitalismo se fará acompanhar por uma forma de heteronomia, que seria própria da nova fase (FERNANDES apud CARDOSO, 2005, p. 17).
\end{abstract}

Então, através da categoria de capitalismo dependente, a questão da modernização é problematizada. Em uma análise sistêmica, a diferença no interior do sistema econômico mundial é atribuída ao progresso técnico, ou seja, as diferenças existem porque o progresso científico e tecnológico dos países do centro e da periferia é diferente. Contudo, como o progresso caminha para a mesma direção, as diferenças podem ser superadas em um momento histórico futuro. Nessa análise, a diferenciação interna do sistema econômico é atribuída, somente, ao progresso científico e tecnológico. A solução para superar essas diferenças é o desenvolvimento das regiões periféricas através da industrialização dessas regiões, ou seja, a análise tem como horizonte o limite de elaborar políticas estratégicas para alcançar o desenvolvimento. (Ibidem).

Para Florestan Fernandes, a análise sistêmica, ao desconsiderar as determinações históricas do modo de produção capitalista estimula uma modernização através da expansão industrial: “[...] uma industrialização divorciada dos interesses nacionais das sociedades que o absorvem, as quais se tornam, em consequência, crescentemente subjugadas aos países cujas economias controlam o processo a partir de fora" (Ibidem, p. 13).

A partir da contribuição de Fernandes (1975) e Cardoso (1978, 1996, 2005, 2006), podemos destacar que o processo de modernização da sociedade brasileira, entre os anos de 1930 e 1970, com ênfase nas décadas de 1950 e 1960², foi baseado na perspectiva de que a industrialização iria estimular o desenvolvimento econômico e colocaria o país no caminho de alcançar o progresso em diversas áreas, incluindo o progresso científico e tecnológico, retirando-o do atraso. Essas questões trazem indícios que nos permitem relacionar a modernização do ensino superior brasileiro, entre as décadas de 1930 e 1970, à necessidade de industrialização do país.

${ }^{2}$ Cf. CARDOSO, Miriam. Ideologia do desenvolvimento Brasil: JK-JQ. Rio de Janeiro: Paz e Terra, 1978.

\begin{tabular}{|l|l|l|l|l|} 
Revista Dialectus & Ano 1 & n. 2 & Janeiro-Junho 2013 & p. 211-227 \\
\hline
\end{tabular}


Nesse período, a luta pela modernização e implantação da universidade no Brasil proporcionou várias mudanças de posição entre as frações da classe dominante (burguesia industrial e oligarquias) para tomar a direção desse processo, principalmente, no primeiro momento, entre 1930 e 1945 . No momento em que a exigência da modernização do ensino superior ganha relevo com a participação dos estudantes exigindo a reforma universitária, no fim da década de 1940 e por toda a década de 1950, a luta pela direção do processo se intensifica. Mas, mesmo essa luta tendo se intensificado, os problemas estruturais, que a expansão do sistema de produção capitalista causou à sociedade brasileira, foram colocados em um plano secundário pela difusão da ideia de que a industrialização associada ao progresso da ciência e das técnicas resolveria esses problemas. Contribuíram para esse cenário o golpe militar de 1964, a legislação sobre o ensino superior produzida depois do golpe e a crença de que o progresso científico ajudaria a construir uma sociedade igualitária.

Segundo o Parecer nº 977/65, a pesquisa é função primordial dos programas de mestrado e doutorado, e possui uma relação estreita com o progresso da ciência. Nesse sentido, recorremos à contribuição de Elizabeth Macedo e Clarilza Sousa, quando elas afirmam que: “em áreas como a educação, praticamente, toda pesquisa é desenvolvida nos programas de pós-graduação ou por sujeitos formados para a pesquisa nesses programas" (MACEDO; SOUSA, 2010, p. 166). Essa tendência atual da pós-graduação stricto sensu em educação mencionada por Macedo e Sousa começou a ser desenhada a partir de meados da década de 1960, quando,

\footnotetext{
As recomendações dos pareceres n. 977/65 e n. 77/69, embora não obrigatórias, foram seguidas à risca pelos cursos, na medida em que era a partir delas que seu funcionamento era autorizado, condição fundamental para a validação dos certificados e para pleitear financiamento junto aos órgãos estatais. (MACEDO; SOUSA, 2010, p. 170).
}

Neste caso, destacamos que as recomendações definidas por lei, para o processo de modernização do ensino superior brasileiro, segundo Macedo e Sousa foram cumpridas à risca na área da educação. A meu ver, o cumprimento dessas recomendações dialogou com a difusão do que Cardoso (1978) denominou de ideologia do desenvolvimento. Para exemplificar a difusão dessa ideologia nas políticas destinadas à pós-graduação stricto sensu recorremos aos objetivos previstos nos Planos Nacionais de Pós-graduação (PNPGs).

O objetivo geral estabelecido no I Plano Nacional de Pós-Graduação (I PNPG, 1975-1979), plano que pretendeu organizar a aplicação das normas contidas nos

\begin{tabular}{|l|l|l|l|l|} 
Revista Dialectus & Ano 1 & n. 2 & Janeiro-Junho 2013 & p. 211-227 \\
\hline
\end{tabular}


Pareceres $n^{\text {o }}$ 977/65 e $n^{\text {o }} 77 / 69$, foi o de "formar, em volume e diversificação, pesquisadores, docentes e profissionais e encaminhar e executar projetos de pesquisa, assessorando o sistema produtivo e o setor público" (BRASIL, 2005, p. 12). Esse objetivo geral da pós-graduação brasileira, a meu ver, está orientado pelo tema do desenvolvimento. Através da execução do I PNPG (1975-1979), a pós-graduação cumpriria o papel de formar profissionais para o sistema produtivo e o setor público, sendo responsável, também, pelo desenvolvimento do processo de industrialização do país e pelo desenvolvimento do aparelho de Estado.

Neste contexto, desde o I PNPG (1975-1979), as ações previstas buscaram superar a expansão espontânea dos cursos de mestrado e doutorado: "a expansão deveria tornarse objeto de planejamento estatal, considerando a pós-graduação como subsistema do sistema universitário e este, por sua vez, do sistema educacional. Deveria então estar integrada às políticas de desenvolvimento social e econômico" (BRASIL, 2005, p. 12).

No II PNPG (1982-1985), o objetivo central, tal como o objetivo definido no I PNPG (1975-1979), continuou sendo a formação de recursos humanos. Todavia, esse objetivo foi associado à qualidade do ensino superior, com ênfase na pós-graduação. Para isso, o II PNPG destacou a necessidade de melhorar a avaliação da pós-graduação, que existia desde 1976 (Ibidem).

O III PNPG (1986-1989) possuía o objetivo de proporcionar um desenvolvimento científico que impulsionasse o processo de independência econômica, científica e tecnológica do país:

\footnotetext{
Elaborado no mesmo período do I Plano Nacional de Desenvolvimento (PND) da Nova República, expressa uma tendência vigente àquela época, a conquista da autonomia nacional [...]. No que se refere à pós-graduação, essa idéia se expressa na afirmação de que não há um quantitativo de cientistas suficiente para se atingir plena capacitação científica e tecnológica, tornando- se importante um progresso da formação de recursos humanos de alto nível, considerando que a sociedade e o governo pretendem a independência econômica, científica e tecnológica para o Brasil, no próximo século (BRASIL, 2005, p. 13).
}

Para alcançar esse objetivo, o plano previu o desenvolvimento de pesquisas pelas universidades e a integração entre a pós-graduação e o sistema de ciência e tecnologia (idem).

Como o IV PNPG não teve a sua elaboração concluída, se passaram quinze anos até que um novo plano fosse concluído. O V PNPG (2005-2010) entrou em vigor com o objetivo de garantir o fortalecimento das bases científica, tecnológica e de inovação; a

\begin{tabular}{|l|l|l|l|l|} 
Revista Dialectus & Ano 1 & n. 2 & Janeiro-Junho 2013 & p. 211-227 \\
\hline
\end{tabular}


formação de docentes para todos os níveis de ensino e a formação de profissionais para o mercado não-acadêmico.

Em resumo, sobre a modernização do ensino superior brasileiro entre as décadas de 1930 e 1970, a característica marcante é o fato de que a universidade brasileira, para se modernizar, precisou se organizar através da diversificação ou variação vertical de níveis, com a separação entre os cursos de graduação e os de pós-graduação stricto sensu, os primeiros dedicados ao ensino e os segundos dedicados à pesquisa.

A partir de agora apresentaremos uma crítica ao método científico universal porque entendemos que a difundida ideia de modernização de diversos setores da sociedade brasileira, principalmente a do ensino superior, através do progresso da ciência e das técnicas dialoga, em grande parte, com a perspectiva científica que compreende que o real pode ser apreendido através da canonização do método científico.

\section{Reflexão crítica sobre o método científico}

A oposição entre a epistemologia cartesiana e a epistemologia da ciência contemporânea é o ponto inicial da reflexão que Miriam Limoeiro Cardoso realiza sobre o método científico, para a autora é importante duvidar da tranquilidade proveniente de uma formalização capaz de universalizar perguntas e respostas independente do objeto a ser pesquisado e da área específica da pesquisa. Segundo Cardoso (1976), o pesquisador não pode adotar padrões estabelecidos do método científico sem realizar uma discussão mais profunda dos critérios que garantem a cientificidade, para ela é necessário explicitar esses critérios através da crítica ao método científico, crítica que extrapola os limites de um debate no interior do próprio método. Neste caso, o método faz parte de um conjunto responsável pela elaboração do conhecimento científico.

\footnotetext{
Entende-se o método como parte de um corpo teórico integrado, em que ele envolve as técnicas, dando-lhes sua razão, perguntando-lhes sobre as possibilidades e as limitações que trazem ou podem trazer às teorias a que servem, no trabalho sobre o seu objeto. A reflexão é aqui necessariamente retorno do método sobre si mesmo, questionamento dos seus próprios fundamentos, revisão crítica (CARDOSO, 1976, p. 62).
}

O questionamento dos fundamentos do método, de acordo com Cardoso (1976), é possível quando conduzimos o raciocínio até o plano epistemológico, em um movimento que permite um distanciamento dos atributos do método e uma aproximação das suposições em que se baseia. Esse movimento possui a capacidade de questionar as

\begin{tabular}{|l|l|l|l|l|} 
Revista Dialectus & Ano 1 & n. 2 & Janeiro-Junho 2013 & p. 211-227 \\
\hline
\end{tabular}


evidências de uma epistemologia espontânea na qual o pesquisador é considerado como um indivíduo concreto, personalizado, que investiga um pedaço da realidade, também concreto.

Segundo Cardoso (1976), o conhecimento científico é o resultado da relação entre um sujeito que busca conhecer e o objeto de sua preocupação, nesse sentido ele se expressa em uma relação determinada principalmente pela construção elaborada a partir da explicação parcial disponível no momento de definição das estratégias utilizadas para abordar o objeto a ser investigado.

\begin{abstract}
Cabe notar que o relacionamento pensamento-objeto não é feito fundamentalmente a partir de cada ser pensante individual e específico com seu objeto específico, mas está baseado na explicação parcial concretamente aceita pela sociedade ou pelo grupo social, conforme ela é assimilada pelo sujeito, tendo importância particular a sua posição dentro dela ou dele. As explicações que fornecem as bases para o estabelecimento da relação entre o objeto a estudar constituem atualmente parte do conhecimento que a ciência elaborou e cuja utilização social conduziu à sedimentação do saber socializado (CARDOSO, 1976, p. 64).
\end{abstract}

Sobre a relação sujeito-objeto é importante ressaltar, de acordo com Cardoso, que apesar de todo esforço se dirigir para a explicação do objeto a ser investigado não é ele quem comanda o processo de investigação "No fundo, é a realidade que importa, mas não é ela que comanda o processo da sua própria inteligibilidade" (CARDOSO, 1976, p. 65).

Neste contexto, a crítica ao método científico elaborada por Cardoso atribui à relação sujeito-objeto um lugar diferente do lugar atribuído por uma epistemologia espontânea. Para Cardoso, na construção de um objeto de conhecimento não cabe o entendimento de que o pesquisador individual se relaciona com um objeto real (concreto), a marca dessa construção é a relação entre a teoria explicadora e aquilo que ela explica.

\footnotetext{
Atente-se, no entanto, que não é neutralidade que se está pedindo a ele (pesquisador), mas participação crítica, vontade, empenho em conseguir descobrir, melhor dizendo construir uma explicação precisa, capaz de satisfazer o nível de exigência requerido. Trata-se, sem dúvida, de uma construção, dominada por um projeto, a teoria em ação, que o cientista tenta desenvolver erigindo em nova teoria (CARDOSO, 1976, p. 67).
}

A explicação capaz de satisfazer o nível de exigência requerido pelo processo de construção de um objeto de conhecimento é uma explicação que surge quando um corte epistemológico estabelece limites na relação entre a teoria e o objeto real, esses limites são estabelecidos através da crítica as bases da explicação anterior do objeto real que será pensado a partir de uma construção que não se contenta com a explicação fornecida

\begin{tabular}{|l|l|l|l|l|} 
Revista Dialectus & Ano 1 & n. 2 & Janeiro-Junho 2013 & p. 211-227 \\
\hline
\end{tabular}


pelo senso comum. Segundo Cardoso, o corte epistemológico é necessário para a construção de um objeto de conhecimento porque as explicações do senso comum se baseiam em um longo processo de sedimentação do todo teórico anterior e impedem a crítica aos fundamentos teóricos de uma determinada teoria, só o corte epistemológico permite o acesso a uma formulação que nega o conhecimento elaborado anteriormente em uma área específica.

O conhecimento que se tinha conseguido elaborar na área do saber em pauta, pois, não se apresenta como acabado ou definitivo. Mas a sua validade, assim como a sua limitação só são compreensíveis a partir da formulação que o nega e com a qual a ciência progride (CARDOSO, 1976, p. 68).

A noção de corte epistemológico contraria os partidários do método científico universal porque introduz a ideia de descontinuidade, como uma característica marcante da ciência contemporânea, ao invés de operar com as ideias de acumulação e continuidade na produção científica. De acordo com Cardoso, associado à noção de corte epistemológico temos rupturas entre teorias científicas, no entanto, essas rupturas não eliminam as explicações teóricas anteriores, “[...] quando ocorre no domínio científico uma ruptura, ela não elimina a verdade anteriormente aceita como se deixasse de ser científica. A negação que sobre ela se exerce é de outra espécie” (CARDOSO, 1976, p. $70)$.

Ao pensar a ciência como um corpo teórico já constituído Cardoso envolve o método em um conjunto integrado do qual fazem parte também teoria, objeto científico, técnica, objeto real, experiência infirmadora, e experiência, para a autora esse conjunto integrado forma um processo constante de pesquisa em inter-relação com os produtos intelectuais desta pesquisa. $\mathrm{O}$ funcionamento desse conjunto integrado é ao mesmo tempo a teoria em ação e a possibilidade de surgimento de uma nova teoria.

Segundo Cardoso, ao fazermos uma teoria entrar em ação nos apoiamos naquilo que já dispomos e conseguimos entender dela, esse guia teórico que serve de apoio é também uma limitação, no entanto, ele crucial para o trabalho teórico, ele permite apreendemos uma parcela da realidade dentro de limites específicos, e nunca tal como ela seja, mas sempre como a conseguimos ver. O surgimento da nova teoria ocorre quando a ruptura entre teorias consegue estabelecer a mudança do objeto de conhecimento.

Vejamos, a seguir, a explicação do funcionamento desse conjunto integrado.

Aquela teoria e aquele objeto real, ambos específicos de um momento determinado do desenvolvimento científico interagem, formando a experiência, que adere a suas especificidades, orientada pela teoria. $\mathrm{O}$ 
método, pois, se exerce no estabelecimento da consequência teórica desta relação, orientada teoricamente, entre a teoria base e o real a que se refere e para o qual pretende apresentar uma explicação válida. Como resultado desse exercício metódico fica construído o objeto do conhecimento, objeto científico. Este é um ponto em que a técnica começa a ser requisitada, uma técnica tal que possa ser produtiva e eficiente diante daquela tripla especificidade, relacionando objeto científico e objeto real (CARDOSO, 1976, p. 73).

Ao afirmar que o método faz parte de um conjunto integrado, Cardoso chama a atenção para o equívoco de adotar um tratamento diferenciado para o método,

\begin{abstract}
A modificação de uma (parte) acarreta modificações nas demais e este processo de transformação se dá quando, posto à prova o conjunto, como um todo ou mesmo numa das relações que o compõem, ele não resiste; quando é negado na prática e se reduz aos limites que a experiência lhe impõe, permitindo uma formulação. Nenhum dos seus termos pode ser transferido a outro conjunto impunemente (CARDOSO, 1976, p. 74).
\end{abstract}

E indo adiante em sua crítica, Cardoso afirma que se o poder da teoria sofre modificações no decorrer do tempo marcado pelas descontinuidades das novas descobertas científicas, com o método não poderia ser diferente. “Ao caráter transitório do conhecimento científico substantivo corresponde o caráter não absoluto do método: não há um conjunto de normas que garantam a cientificidade" (Ibidem). Para a autora as transformações dos conjuntos teóricos, transformações nas relações básicas, alteram o método empregado na construção do objeto de conhecimento e, por isso, o controle da aplicação do método não é suficiente para garantir a resolução dos problemas da pesquisa.

Tendo a ciência uma história é mister do cientista aprender com ela. E assim como ela mostra a falência de alguns métodos, ela indica a fecundidade de outros. A cada momento do desenvolvimento científico algum ou alguns métodos são apontados como os mais eficientes no tratamento de tais ou quais problemas. Até que outros os suplantem. A ciência não tem preconceitos. Ela não é mera sistemática, não é simples classificação; ela se abre para o conhecer, é apenas isso que importa, por isso que sofre tantas vezes com oposição do social (Ibidem, p. 77).

É possível dizer, de acordo com Cardoso, que a supervalorização da ciência em relação aos demais tipos de conhecimento está associada a uma supervalorização do método científico. Neste caso, o método científico surge como instrumento capaz de relacionar dados através do julgamento das variáveis segundo regras fixadas na ciência o que permite um distanciamento de outros tipos de explicação do real e garante à ciência um lugar de destaque mantido graças à 'sofisticação' e ao 'rigor' do método científico. “A qualificação de um método como o método científico o opõe aos demais, portanto não científicos" (Ibidem, p. 82). 
Segundo Cardoso, a supervalorização da ciência contribui para o entendimento de que ela seja isolada e inteiramente autônoma da sociedade, com a ciência é possível se estabelecer a 'verdade' das coisas e, ao contrário, a não-ciência pode ser classificada como opinião, como ideologia por não seguir as regras fixadas pelo método científico. "Daí segue a vantagem em dispor deste método milagroso, conhecê-lo e dominá-lo enquanto conjunto de técnicas que, se bem manejadas, conduzem à descoberta da verdade" (Ibidem, p. 83).

Adotar o pressuposto de que é possível descobrir a 'verdade' através do método supõe ele como elemento capaz de desvendar a realidade guardando desta sua objetividade, preservando o objeto de pesquisa de qualquer interferência, de qualquer contaminação que atrapalhe a pesquisa (Ibidem).

Neste contexto, Cardoso nos diz que:

O esforço da pesquisa é apenas técnico, nada teórico. "Teórico" é unicamente o seu resultado. Sendo a técnica estritamente concreta, a neutralidade dela depende tão somente da neutralidade de quem a utiliza. A partir daí o foco é centrado no pesquisador individual. $O$ melhor cientista seria a máquina, incapaz de pensar, mas com ótimo desempenho técnico (Ibidem, p. 83).

Nesta perspectiva a realidade está à mostra e o 'erro' presente na investigação corresponde a uma cópia mal feita da realidade, a um 'erro' metódico na obtenção do saber ou às divergências provenientes de subjetividades distintas. Cardoso enfatiza que essa perspectiva científica se baseia na "ilusão do real transparente, mostrando-se e fornecendo dados que o espelham" (Ibidem, p. 84), isto porque o fundamento do conhecimento reside na transposição do objeto real para dentro do pensamento, uma transposição que tenta resguardar a inteireza do objeto real para dentro do pensamento do pesquisador, e, então, pode denominar de 'conceito' o resultado desse processo de abstração.

\footnotetext{
Desse modo, entre as suposições básicas do método científico contam-se as seguintes: recolhem-se indícios do real para com eles compor, sistematizando, uma "cópia" do objeto. A verdade dessa cópia se confunde com a objetividade, quando várias subjetividades concordam quanto a ela. Considerando o objeto como o objeto real que se oferece, consistindo esta oferta nos "dados" - o sujeito não devendo interferir, mas apenas captar estes dados e trabalhá-los, o conhecimento não é senão o resultado da manipulação deles e o essencial para consegui-lo é o método (técnica) adequado(Ibidem).
}

De acordo com Cardoso, conceber o objeto real como algo que se oferece ao pesquisador proporciona o surgimento de uma 'ilusão empirista'. O terreno propício para o desenvolvimento dessa ilusão é certo tipo de filosofia da ciência que afirma que existe uma separação entre filosofia e ciência e chama para si a responsabilidade de

\begin{tabular}{|l|l|l|l|l|} 
Revista Dialectus & Ano 1 & n. 2 & Janeiro-Junho 2013 & p. 211-227 \\
\hline
\end{tabular}


definir as tarefas da ciência. Ao contrário dessa posição, a autora nos diz que "se, porém, não há ciência sem filosofia, se não há filosofia sem ciência, se em cada uma cabe a outra sem ferir suas especificidades, perde o sentido pensar em termos de uma filosofia da ciência" (Ibidem, p. 85).

A ciência contemporânea não pode ser explicada, conforme Cardoso, nos limites de uma filosofia da ciência, além disso, ela diz que identificar filosofia da ciência e metodologia científica é um engano porque o exercício desta última tem suas raízes na ciência e, portanto, não é especificamente um exercício filosófico. O exercício metódico da prática científica é derivado da atividade de pesquisa, por isso, não faz sentido falarmos em cientificidade de uma atividade estritamente filosófica, tal como, a praticada por uma filosofia da ciência.

Segundo Cardoso, a complexidade do real impõe ao conhecimento científico uma prática de construir representações que vão explicando o real em um processo infinito de aproximações. E a construção dessas representações supõe uma transformação infinita das teorias que se propõem a explicar o real. E assim,

\begin{abstract}
A teoria está sendo sempre transformada. Parte-se de uma teoria-base para problematizar o objeto que lhe é próprio, quando ele aparece como um desafio. Mas também ela se problematiza enquanto faz ciência. O método da problematização dela não é idêntico ao método da problematização que ela faz. Deste modo, fazer ciência transforma incessantemente o método. E é essa capacidade de transformação sempre presente que dá o caráter de científico. Ele só permanece intacto, fechado, se não for posto em prática, ou se o for, mas de forma contrária ao progresso da ciência (Ibidem, p. 86).
\end{abstract}

Conceber o método científico como algo pronto, fechado em si mesmo, é uma forma de proceder que entende a investigação científica como um processo meramente técnico, como a escolha do melhor método disponível para explicar o objeto de pesquisa dentro de um 'quadro de referência teórico'. Essa escolha se detém em um forte apelo à realidade e faz manifestar uma dificuldade do senso comum na explicação que pretende ser científica (cf. CARDOSO, 1976).

Como então fugir desse fechamento? Segundo Cardoso, é importante percebemos que ao fazermos ciência a renovação é permanente.

Fazendo-se a ciência, a renovação é permanente: da teoria, do método, da técnica, do objeto. Pensando a ciência no tempo, olhando os grandes momentos de que se compõe, concluímos que as autênticas revoluções que os constituem não se dão por pura continuidade com a teoria, o método, a técnica e o objeto anterior, nem por algum processo que nada tenha a ver com eles (como uma geração espontânea). Dão-se através de uma forma específica de negação de sua própria base, do seu próprio ponto de partida (Ibidem, p. 86).

\begin{tabular}{|l|l|l|l|l|}
\hline Revista Dialectus & Ano 1 & n. 2 & Janeiro-Junho 2013 & p. 211-227 \\
\hline
\end{tabular}


Para Cardoso, o corte epistemológico e a ruptura entre teorias é um movimento que permite a renovação da ciência e, consequentemente, do conjunto integrado composto pela teoria, método, objeto do conhecimento, técnica, objeto real, experiência infirmadora e experiência. A autora afirma que o conhecimento científico nunca parte do total desconhecimento, “[...] toda a investigação supõe um projeto, um corpo teórico que lhe dá forma, orientação e significado, [...]” (Ibidem), dessa forma, a perspectiva de investigação científica defendida por Cardoso é totalmente diferente da perspectiva que trabalha com a ideia de que o objeto real se revela ao pesquisador e pode ser apreendido pelo método científico universal.

O problema principal da defesa do método científico, conforme Cardoso, é o esquecimento da teoria, porque ao tratar isoladamente o método a totalidade teórica é decomposta em partes que possuem autonomia e geram uma deformação no desenvolvimento teórico. Nesse sentido, a meu ver, a crítica que Cardoso fez à preocupação exagerada com o método científico por parte dos empiristas da área de ciências sociais na década de 1970 é uma crítica atual.

Entendo que essa atualidade pode ser expressa no seguinte trecho:

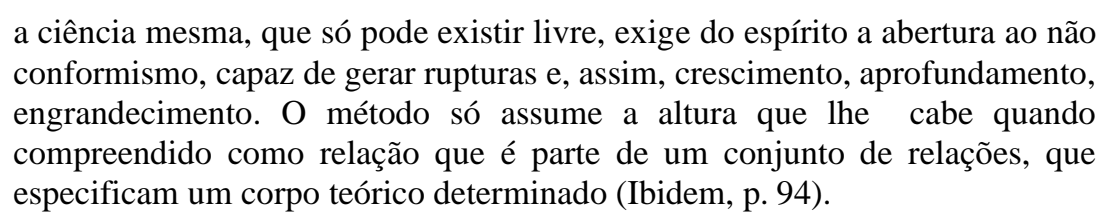

Toda vez que a pesquisa científica for canonizada, inclusive na área da educação, podemos retomar a crítica de Miriam Limoeiro Cardoso ao método científico universal e dizer que o desenvolvimento teórico acontece através de rupturas e da abertura do espírito ao não conformismo, uma postura que vai de encontro ao ritual estabelecido, à regra fixa e ao que é denominado pelos empiristas como método científico.

\section{Considerações finais}

Depois de apresentarmos aspectos da modernização do ensino superior brasileiro entre as décadas de 1930 e 1970 e a crítica ao método científico realizada por Miriam Limoeiro Cardoso entendemos que os sentidos atribuídos à ciência no processo de modernização do ensino superior brasileiro foram definidos em uma perspectiva científica que associa o progresso da sociedade em geral ao progresso científico. 
Nesse sentido, a perspectiva científica que fundamenta o Parecer $n^{\circ} 977 / 65$, a Lei $n^{\circ} 5.540 / 68$, o Parecer $n^{\circ} 77 / 69$, instrumentos legais que regulamentaram a modernização do ensino superior nas décadas de 1960 e 1970, é uma perspectiva de ciência que, em grande parte, subordina o desenvolvimento científico ao seguimento de um ritual estabelecido através de regras fixas, neste caso, o desenvolvimento científico mantém relação, apenas, com o movimento de construção interna da própria ciência.

No entanto, baseado em Cardoso (1996), entendemos que o desenvolvimento da ciência mantém vínculos com o processo de institucionalização da pesquisa, vínculos com as condições histórico-sociais, que são responsáveis pelos avanços que o conhecimento científico consegue obter. E assim, conforme Cardoso (1978) e Fernandes (1975), afirmamos que a ideologia do desenvolvimento difundida em uma região na qual o modo de produção capitalista configurou como dependente contribuiu para o processo de afirmação da ciência através das certezas provenientes do uso do método científico, um processo que na área da educação - área que, segundo Macedo e Sousa (2010), seguiu à risca as orientações dos Pareceres $n^{\circ}$ 977/65 e $n^{\circ}$ 77/69 - fez parte do contexto de implantação da pós-graduação stricto sensu.

Nesse sentido, as subáreas que compõe a área da educação atualmente podem ser explicadas levando-se em consideração que os sentidos atribuídos à ciência desde o período de implantação da pós-graduação em educação stricto sensu não sofreram modificações profundas, porém, essa explicação natural das pesquisas em educação, ao invés de contribuir para entendermos as determinações do desenvolvimento das subáreas da educação, contribui para tratarmos as pesquisas em educação como uma unidade homogênea imutável ao longo de sua história. Um erro que denomino de naturalização da pesquisa em educação.

\section{Referências Bibliográficas}

BRASIL. Ministério da Educação. V Plano Nacional de Pós-graduação. Brasília, DF, 2004. Disponível em: <http://www.capes.gov.br>. Acessado em: 24 de julho de 2009.

CAMPOS, Maria; FÁVERO, Osmar. A pesquisa em educação no Brasil. In: Cadernos de Pesquisa. São Paulo, Fundação Carlos Chagas, n. 88, p. 5-17, 1994.

CARDOSO, Miriam. A ideologia do desenvolvimento - Brasil: JK - JQ. Rio de Janeiro, Paz e Terra, $2^{a}$ ed,1978. 
. Florestan Fernandes: a criação de uma problemática. In: Estudos

Avançados, São Paulo, v.10, n. 26, p.1-26, 1996.

. O mito do método. In: Boletim Carioca de Geografia, Rio de Janeiro, 1976.

. Sobre a teorização do Capitalismo Dependente em Florestan Fernandes. In: FÁVERO, Osmar. Democracia e Educação em Florestan Fernandes. São Paulo: Autores Associados, 2005.

. Sobre as relações sociais capitalistas. In: LIMA, Júlio; NEVES, Lúcia. Fundamentos da educação escolar do Brasil contemporâneo. Rio de Janeiro: Editora FIOCRUZ/EPSJV, 2006.

FÁVERO, Maria de Lourdes. A universidade no Brasil: das origens à reforma universitária de 1968. In: Educar, Curitiba, n. 28, p. 17-36, 2006.

FERNANDES, Florestan. Universidade brasileira: reforma ou revolução? São Paulo, Alfa-ômega, 1975.

PARECER 77/69. Documenta, nº 98, fev. p.128-132, 1969.

PARECER 977/65. Revista Brasileira de Educação. n. 30, p. 162-173, 2005. 